\title{
South Korean nurses' knowledge of delirium in hospitalised older adults with and without dementia
}

\author{
Yun Kang ${ }^{1}$ and Chang Seung Park ${ }^{2}$ \\ ${ }^{1}$ Department of Nursing, Changwon National University, South Korea \\ ${ }^{2}$ School of Nursing, Cheju Halla University, South Korea
}

\begin{abstract}
Aim: To assess South Korean nurses' knowledge of delirium in hospitalised older adults with and without dementia.

Methods: A cross-sectional survey study was conducted in July 2013 and a convenience sample of 101 registered nurses from inpatients wards of one regional general hospital in South Korea was recruited and completed the case vignettes.

Results: This study showed that the registered nurses' knowledge of the recognition and management of hypoactive delirium and hypoactive delirium superimposed on dementia was poor and inappropriate for clinical practice, compared with their knowledge of dementia, hyperactive delirium, and hyperactive delirium superimposed on dementia.

Conclusion: The findings of this study highlights the need to educate South Korean nurses on dementia, delirium, and delirium superimposed on dementia care because older adults, particularly those with dementia, are at high risk of developing this complication while hospitalised.
\end{abstract}

\section{Introduction}

In South Korea, the prevalence of dementia is rapidly increasing alongside the aging of the population. The prevalence of dementia among South Korean older adults (age $\geq 65$ years) was $8.4 \%$ in 2008 , and it is expected to increase to $9.7 \%$ by 2020 and to $13.2 \%$ by 2050 [1]. The inpatient hospital costs for Alzheimer's disease, the most common form of dementia has also been reported as being greater than for any other disease in South Korea [2]. In the first half of 2015, the total inpatient hospital spending was USD \$ 388,555,222 for Alzheimer's disease and was USD \$ 6,548 per person in South Korea [2]. The rapid increase in the population of people with dementia has the potential to increase the likelihood of health care professionals in hospitals in South Korea encountering older adults with delirium superimposed on dementia (DSD) in their daily practice.

DSD occurs when a person with pre-existing dementia develops delirium [3]. Delirium is four times more likely to occur in hospitalised older adults with dementia compared with hospitalised older adults without dementia [4]. DSD is associated with higher health care costs and adverse outcomes such as worse functional outcomes and higher mortality rates when compared with patients with dementia alone or delirium alone [5,6]. DSD is also distressing for patients [7] and is likely to significantly increase patients' need for assistance from registered nurses (RNs) and family caregivers.

Recently, Western studies have assessed acute care nurses' knowledge of delirium in hospitalised older adult with and without dementia, using case vignettes [3,8]. Fick, Hodo [3] reported more knowledge of the recognition and management of dementia, hyperactive delirium and hyperactive DSD, compared with hypoactive delirium and hypoactive DSD, using the five vignettes. Bellelli, Morandi [8] reported poor knowledge of the recognition of hypoactive delirium and
DSD, using the two vignettes. However, in South Korea, most nursing research has focused on delirium as a single clinical entity in hospital settings [9-12], and little attention was given to DSD recognition and management in hospital settings. The aim of this study was to assess South Korean nurses' knowledge of delirium in hospitalised older adults with and without dementia.

\section{Methods}

This cross-sectional survey study was conducted in one regional general hospital in South Korea.

\section{Participants and data collection}

Information seminars providing oral and written information about the study were held and a convenience sample of 101 RNs from inpatients wards, excluding critical care, paediatric and obstetric units was recruited. They completed the survey in July 2013.

\section{Outcome measures}

Knowledge of dementia, delirium, and DSD was measured using five case vignettes [3] which illustrate hospitalised older adults with dementia, hypoactive delirium, hyperactive delirium, hyperactive DSD, and hypoactive DSD. The case vignettes focus on assessing nurses' ability to identify different subtypes of delirium and DSD in

Correspondence to: Yun Kang, Department of Nursing, Changwon National University, 20 Changwondaehak-ro Uichang-gu Changwon-si, Gyeongsangnam Province 641-773, South Korea, Tel: 820127971295; E-mail: yun.kang@griffithuni.edu.au

Key words: delirium, delirium superimposed on dementia, nursing, case vignettes

Received: January 07, 2017; Accepted: January 27, 2017; Published: January 30, 2017 
a standardised format, as well as to gather qualitative data from the nurses related to how they would assess and manage delirium [3]. For each vignette, the individual case symptoms and behaviours are presented, and respondents are asked to answer nine multiple choice and open-ended questions related to the patients' mental status, the type of change (i.e., acute or chronic), what was happening to the patient (i.e., recognition of delirium and/or dementia), whether or not they would call the physician to tell them about the behaviour, and whether or not they would call the physician to request a medication. Open-ended questions related to the cause of the patient symptoms, how they would manage the problem, and what if any medications they would administer for the problem are also provided [3].

The original vignettes underwent an expert validation process prior to use [3]. In this study, the English version of the vignettes was translated into Korean by the first author. Two bilingual South Korean nursing professors conducted back-translation. No significant discrepancies between the original English version and the backtranslation version were determined by agreement between the first author and the bilingual South Korean nursing professors who carried out back-translation. To validate the concepts measured and any issues regarding wording of the vignettes [13], along with back-translation the Korean version was pilot-tested by a convenience sample of six South Korean $4^{\text {th }}$-year undergraduate nursing students at one private university who had completed the subject and clinical placement of gerontological nursing.

\section{Data analysis}

Quantitative data were analysed using the Statistical Package for Social Science (SPSS), version 21.0. Participant characteristics and multiple-choice questions of case vignettes were analysed descriptively. The manifest content analysis for the open-ended questions of case vignettes was conducted to describe themes that arose from the occurrence of specific words or phrases as distinguished from latent content analysis [14]. In this study, the theme identification process based on the steps by Norwood [14] informed the qualitative data analysis: data familiarisation through reading and re-reading the transcripts; generating initial codes in a systematic fashion across the whole data set, using an inductive analysis process to allow themes to emerge from the data; reviewing themes to ensure internal and external validity; and defining and naming themes. The first author conducted the initial analysis of data in the original language. To improve consistency and reliability and to minimise bias, the initial analysis was reviewed, discussed and refined with the research team until a consensus was reached.

\section{Ethical considerations}

The permission from the institution representative where the data were collected was obtained because related hospital did not have the Institutional Review Board (IRB) during that period. All participants were given an information sheet and they signed a consent form. The confidentiality of both the participants and the hospital involved were assured.

\section{Results}

\section{South Korean nurse sample}

The 101 female RNs were aged between 23 and 57 years $(M=34.4$, $\mathrm{SD}=8.1)$. The majority of participants $(\mathrm{n}=85)$ were involved in direct patient care. In this study, gerontological nursing education refers to any gerontological education, either undergraduate or continuing (and/or in-service) education. Seventy-nine participants reported that they studied content related to older people with and without dementia and/or delirium in medical-surgical or mental health nursing subjects in their undergraduate programs. Seven participants reported that they did not have any formal education on gerontological nursing. Table 1 provides additional demographic information.

\section{Quantitative results}

Ninety-one participants reported that they had experience in caring for older patients with the symptoms of hyperactive delirium, and hyperactive DSD. Seventy-nine participants had experience caring for older patients with the symptoms of hypoactive delirium and hypoactive DSD.

Ninety-five and ninety-three participants correctly answered acute onset as the key feature of delirium in the hyperactive delirium and hyperactive DSD vignettes, respectively. Sixty-one and fifty-eight

Table 1. Personal and Professional Characteristics of Participating Nurses $(N=101)$ [Note: Work unit and nursing position title used only at the study hospital site].

\begin{tabular}{|c|c|c|c|c|}
\hline Variable & $\mathrm{N}$ & $\mathrm{M}(\mathrm{SD})$ & Minimum & Maximum \\
\hline Age (years) & 101 & $34.4(8.1)$ & 23.0 & 57.0 \\
\hline Variable & $\mathrm{N}$ & Description & & $\%$ \\
\hline \multirow[t]{2}{*}{ Gender } & 101 & Female & & 100.0 \\
\hline & 0 & Male & & 0.0 \\
\hline \multirow[t]{5}{*}{ Work units/speciality } & 26 & Neurology internal medicine and surgery & & 25.7 \\
\hline & 25 & Gastroenterology internal medicine and surgery & & 24.8 \\
\hline & 20 & Orthopaedic surgery & & 19.8 \\
\hline & 10 & Rehabilitation & & 9.9 \\
\hline & 20 & Respiratory internal medicine & & 19.8 \\
\hline \multirow[t]{2}{*}{ Nursing position title } & 85 & Registered general nurse & & 84.2 \\
\hline & 16 & Charge nurse & & 15.8 \\
\hline \multirow[t]{3}{*}{ Nursing experience(years) } & 57 & $\leq 9$ years & & 56.4 \\
\hline & 30 & 10 years $\leq$ and $\leq 19$ years & & 29.7 \\
\hline & 14 & $\geq 20$ years & & 13.9 \\
\hline \multirow[t]{2}{*}{ Nursing education } & 20 & 4-year Bachelor degree & & 19.8 \\
\hline & 81 & 3-year Associate degrees & & 80.2 \\
\hline \multirow[t]{3}{*}{ Formal education in gerontological nursing } & 79 & \begin{tabular}{|l|l|} 
Yes & Undergraduate
\end{tabular} & & 78.2 \\
\hline & 15 & Continuous (and/or in-service) & & 14.9 \\
\hline & 7 & No & & 6.9 \\
\hline
\end{tabular}


participants answered acute onset as the key feature of delirium for hypoactive delirium and hypoactive DSD vignettes, respectively.

Fifty-seven and seventy-one participants had knowledge of the recognition of hyperactive delirium and hyperactive DSD, respectively. Fifteen and thirteen participants had knowledge of the recognition of hypoactive delirium and hypoactive DSD, respectively.

Eighty-five and seventy-two participants considered to call the oncall physician for managing the symptoms of hyperactive delirium and hyperactive DSD, respectively. Thirty-nine and forty-one participants considered to call the on-call physician for managing the symptoms of hypoactive delirium and hypoactive DSD, respectively.

Ninety-two and seventy-seven participants considered calling the on-call physician for medicating the symptoms of hyperactive delirium and hyperactive DSD, respectively. Thirty-six and thirty-eight participants considered calling the on-call physician for medicating the symptoms of hypoactive delirium and hypoactive DSD, respectively. To manage the symptoms of hyperactive delirium and hyperactive
DSD, Haloperidol and Lorazepam were reported by the participants who considered calling the on-call physician for medication. To manage the symptoms of hypoactive delirium and hypoactive DSD, Trazodone, Lexapro and Quetiapine were reported by the participants who considered calling the on-call physician for medication because the symptoms were incorrectly interpreted as depression. Table 2 provides additional information about the multiple-choice questions about the recognition and management of dementia, delirium and DSD.

\section{Qualitative results}

In terms of the causes, hypoactive delirium had four key responses and included: (1) delirium risk factor; (2) delirium; (3) age-related fatigue, lethargy and depression; and (4) dementia-related mood change. Hyperactive delirium had four key responses and included: (1) delirium risk factors; (2) delirium; (3) dementia-related hallucination and delusion; and (4) stroke. Delirium risk factors of dehydration, drug side effects, environmental change, infection, advanced age, sensory impairment and lack of mobilization were identified by participants as

Table 2. Responses to Multiple-choice Questions of Dementia, Delirium, and DSD.

\begin{tabular}{|c|c|c|c|c|c|}
\hline $\begin{array}{l}\text { Vignette } \\
\text { N (\%) }\end{array}$ & Care experience & Acute onset & Recognition & $\begin{array}{l}\text { Decision to call the on-call } \\
\text { physician for management }\end{array}$ & $\begin{array}{l}\text { Consideration given to calling the } \\
\text { on-call physician for medicating }\end{array}$ \\
\hline Dementia & $\begin{array}{l}\text { Yes: } 86(85.1) \\
\text { No: } 15(14.9)\end{array}$ & Yes: 41 (40.5) & $\begin{array}{l}\text { Dementia: } 59(\mathbf{5 8 . 4 )} \\
\text { Delirium: } 7(6.9) \\
\text { DSD: } 10(9.9) \\
\text { Normal aging: } 25(24.8)\end{array}$ & $\begin{array}{l}\text { Yes: } 6(5.9) \\
\text { No: } 95(94.1)\end{array}$ & $\begin{array}{l}\text { Yes: } 12(11.9) \\
\text { No: } 89(88.1)\end{array}$ \\
\hline $\begin{array}{l}\text { Hypoactive } \\
\text { Delirium } \\
\text { Only }\end{array}$ & $\begin{array}{l}\text { Yes: } 79(78.2) \\
\text { No: } 22(21.8)\end{array}$ & Yes: $61(60.3)$ & $\begin{array}{l}\text { Dementia: } 39(38.6) \\
\text { Delirium: } 15(14.9) \\
\text { DSD: } 13(12.9) \\
\text { Normal aging: } 10(9.9) \\
\text { None of above: } 24(23.7)\end{array}$ & $\begin{array}{l}\text { Yes: } 39(38.6) \\
\text { No: } 62(61.4)\end{array}$ & $\begin{array}{l}\text { Yes: } 36(35.6) \\
\text { No: } 65(64.4)\end{array}$ \\
\hline $\begin{array}{l}\text { Hyperactive } \\
\text { Delirium } \\
\text { Only } \\
\end{array}$ & $\begin{array}{l}\text { Yes: } 91(90.0) \\
\text { No: } 10(10.0)\end{array}$ & Yes: 95 (94.0) & $\begin{array}{l}\text { Dementia: } 2(2.0) \\
\text { Delirium: } 57(\mathbf{5 6 . 4 )} \\
\text { DSD: } 42(41.6)\end{array}$ & $\begin{array}{l}\text { Yes: } 85(84.2) \\
\text { No: } 16(15.8)\end{array}$ & $\begin{array}{l}\text { Yes: } 92(91.1) \\
\text { No: } 9(8.9)\end{array}$ \\
\hline $\begin{array}{l}\text { Hyperactive } \\
\text { DSD }\end{array}$ & $\begin{array}{l}\text { Yes: } 91(90.0) \\
\text { No: } 10(10.0)\end{array}$ & Yes: 93 (92.0) & $\begin{array}{l}\text { Dementia: } 15(14.9) \\
\text { Delirium: } 12(11.9) \\
\text { DSD: } 71 \text { (70.2) } \\
\text { Normal aging: } 1(1.0) \\
\text { None of above: } 2 \text { (2.0) }\end{array}$ & $\begin{array}{l}\text { Yes: } 72(71.3) \\
\text { No: } 29(28.7)\end{array}$ & $\begin{array}{l}\text { Yes: } 77(76.2) \\
\text { No: } 24(23.8)\end{array}$ \\
\hline $\begin{array}{l}\text { Hypoactive } \\
\text { DSD }\end{array}$ & $\begin{array}{l}\text { Yes: } 79(78.2) \\
\text { No: } 22(21.8)\end{array}$ & Yes: 58 (57.4) & $\begin{array}{l}\text { Dementia: } 74(73.3) \\
\text { Delirium: } 3(2.9) \\
\text { DSD: } 13 \text { (12.9) } \\
\text { Normal aging: } 6(5.9) \\
\text { None of above: } 5(5.0)\end{array}$ & $\begin{array}{l}\text { Yes: } 41(40.6) \\
\text { No: } 60(59.4)\end{array}$ & $\begin{array}{l}\text { Yes: } 38(37.6) \\
\text { No: } 63(62.4)\end{array}$ \\
\hline
\end{tabular}

Note: Correct answer is in bold fond. DSD=delirium superimposed on dementia

Table 3. Responses to Open-ended Questions of Dementia, Delirium, and DSD.

\begin{tabular}{|c|c|c|}
\hline Vignette & Key responses on causes & Key responses on management \\
\hline Dementia & $\begin{array}{l}\text {-Alzheimer's disease } \\
\text {-Aging } \\
\text {-Parkinson' disease }\end{array}$ & $\begin{array}{l}\text {-Consultation for diagnosis } \\
\text {-Dementia medication } \\
\text {-Reorientation and reassurance }\end{array}$ \\
\hline $\begin{array}{l}\text { Hypoactive } \\
\text { Delirium } \\
\text { Only }\end{array}$ & $\begin{array}{l}\text {-Delirium risk factors } \\
\text {-Delirium } \\
\text {-Aging-related fatigue, lethargy \& depression } \\
\text {-Dementia-related mood change }\end{array}$ & $\begin{array}{l}\text {-Notify physicians of patients' status and take an order for laboratory testing (e.g., dehydration and inflammation) } \\
\text {-Notify physicians for diagnostic tests of depression } \\
\text {-Check the list of medications that have been administered } \\
\text {-Emotional support and reorientation } \\
\text {-Activity encouragement }\end{array}$ \\
\hline $\begin{array}{l}\text { Hyperactive } \\
\text { Delirium } \\
\text { Only }\end{array}$ & $\begin{array}{l}\text {-Delirium risk factors } \\
\text {-Delirium } \\
\text {-Dementia-related hallucination and delusion } \\
\text {-Stroke }\end{array}$ & $\begin{array}{l}\text {-Notify physicians of patients' status and take an order for medication (antipsychotic or sedative drug) } \\
\text {-Isolation and physical restraint use if aggressive } \\
\text {-Emotional support and reorientation } \\
\text {-Hazard removed for safety }\end{array}$ \\
\hline $\begin{array}{l}\text { Hyperactive } \\
\text { DSD } \\
\text { Only }\end{array}$ & $\begin{array}{l}\text {-Delirium risk factors } \\
\text {-Delirium } \\
\text {-Dementia }\end{array}$ & $\begin{array}{l}\text {-Notify physicians of patients' status and medication (antipsychotic or sedative drug) } \\
\text {-Isolation and physical restraint use if aggressive } \\
\text {-Emotional support and reorientation }\end{array}$ \\
\hline $\begin{array}{l}\text { Hypoactive } \\
\text { DSD }\end{array}$ & $\begin{array}{l}\text {-Delirium risk factors } \\
\text {-Dementia-related depression } \\
\text {-Aging }\end{array}$ & $\begin{array}{l}\text {-Check blood sugar, or vital signs, notify physician of patient's status and take an order for laboratory testing (e.g., } \\
\text { dehydration) } \\
\text {-Assessment of consciousness change }\end{array}$ \\
\hline
\end{tabular}

Note: $\mathrm{DSD}=$ delirium superimposed on dementia 
causes of hypoactive delirium, hyperactive delirium, hyperactive DSD and hypoactive DSD. Table 3 provides additional information about the responses on causes of dementia, delirium, and DSD.

In terms of the management, hypoactive delirium had five key responses and included: (1) notify physicians of patients' status and take an order for laboratory tests for possibility of dehydration and inflammation; (2) notify physicians for diagnostic tests of depression; (3) check the list of medications that have been administered; (4) emotional support and reorientation; and (5) activity encouragement. Hyperactive delirium had four key responses regarding core management and included: (1) notify physicians for medication, such as antipsychotic or sedative drugs; (2) isolation and physical restraint use if aggressive; (3) emotional support and reorientation; and (4) hazard removed for safety. Table 3 provides additional information about the responses on management of dementia, delirium, and DSD.

\section{Discussion}

In the current study, almost RNs reported that they had experienced caring for hospitalised older adults with the symptoms of dementia, hyperactive delirium, hypoactive delirium, hyperactive DSD, and hypoactive DSD represented in the case vignettes. This finding suggests that it is common for South Korean RNs to encounter hospitalised older adults with hyperactive delirium, hypoactive delirium, hyperactive DSD, and hypoactive DSD, as well as dementia, in their daily practice.

There are very few studies in the literature that have assessed the knowledge of acute care nurses to correctly identify and appropriately manage specific situations of dementia, delirium, and DSD subtypes. Fick, Hodo [3] conducted a cross-sectional survey design to assess acute care nurses' knowledge of the recognition and management of dementia, delirium and DSD in the United States (US), using the same case vignettes used in the current study. Consistent with this prior research [3], the nurses in the current study had some knowledge of the recognition of hyperactive delirium and hyperactive DSD. Specifically, higher percentages of nurses in the current study were able to correctly identify hyperactive delirium (56\%) and hyperactive DSD (70\%) compared with $52 \%$ and $59 \%$ in the Fick, Hodo [3] study. In contrast, lower percentages of nurses in the current study were able to correctly identify hypoactive delirium (15\%), hypoactive DSD (13\%) and dementia (58\%) compared with $41 \%, 21 \%$ and $83 \%$ in the Fick, Hodo [3] study.

Consistent with the Fick, Hodo [3] study, in the current study the qualitative responses given by nurses were related to management of the problems, and reflected that even though nurses may have identified the delirium and/or dementia problem incorrectly they appeared to recognise that there was a change in cognitive status requiring further investigation, either through notification of the physician or taking actions such as assessment of glucose levels and vital signs. However, the results from the quantitative data in the current study showed that $39 \%$ of nurses decided to call the on-call physician for the symptoms of hypoactive delirium and $41 \%$ decided to call for the symptoms of hypoactive DSD vignettes compared with $86 \%$ and $65 \%$ in the Fick, Hodo [3] study. This could indicate that less attention has been paid to dementia, delirium and DSD care in nursing education in South Korea. South Korean nurses may assume that the symptoms of hypoactive delirium and/or hypoactive DSD are a normal part of the ageing process or a result of dementia, rather than being related to the symptoms of delirium. In South Korea, family caregivers at the bedside have the most consistent contact with their older family member in acute care settings [15]. Due to a lack of awareness for delirium, family caregivers do not identify the symptoms of hypoactive delirium and/ or hypoactive DSD and do not report these symptoms to staff nurses. This finding highlights the need to educate both acute care nurses and family caregivers on dementia, delirium, and DSD care because older adults, particularly those with dementia, are at high risk of developing this complication while hospitalised.

This study had several limitations. First, this study used selfreported case vignettes to assess nurses' knowledge of the recognition and management of demenita, delirium, and DSD; their actual performance was not measured. This study also included only those who were willing to participate in this study, which reduced the representativeness of the chosen population sample. The small sample with data collection undertaken only in one regional general hospital in South Korea is a further limitation.

\section{Conclusions}

The findings of this study are important because this topic has received little attention in the South Korean context. This study demonstrated that South Korean nurses' knowledge of dementia, delirium, and DSD was inadequate, thus potentially resulting in inappropriate dementia, delirium, and DSD care in practice. The results of this study signify a need for an ongoing educational programme. Therefore, hospital in-service education programs should include dementia, delirium, and DSD care for nurses. This education should be directed towards helping nurses to improve their ability to provide appropriate dementia, delirium, and DSD care.

Nursing students in undergraduate programs should be wellprepared to provide appropriate dementia, delirium, and DSD care before entering a nursing career. Nursing faculty members who are committed to gerontological nursing in undergraduate programs need to advocate for stand-alone gerontology courses to be compulsory and to increase the content of dementia, delirium, and DSD care in these subjects and clinical placements.

\section{Conflict of interest}

No conflict of interest has been declared by the authors.

\section{References}

1. Cho M, Kim K, Kim M, Kim M, Kim S, et al. (2008) Nationwide study on the prevalence of dementia in Korean elders (Registration No. 11-1351000-000227-01). Seoul: Seoul National University Hospital Ministry of Health, Welfare, and Family Affairs.

2. Korea Health Insurance Review and Assessment Service (2015) National Health Service expenditure in the first half of 2015.

3. Fick D, Hodo DM, Lawrence F (2007) Recognizing delirium superimposed on dementia-Assessing nurses' knowledge using case vignettes. J Gerontol Nurs 33: 4047. [Crossref]

4. Franco JG, Valencia C, Bernal C, Ocampo MV, Trzepacz PT, et al. (2010) Relationship between cognitive status at admission and incident delirium in older medical inpatients. J Neuropsychiatry Clin Neurosci 22: 329-337. [Crossref]

5. Fick D, Steis MR, Waller JL, Inouye SK (2013) Delirium superimposed on dementia is associated with prolonged length of stay and poor outcomes in hospitalised older adults. J Hosp Med 8: 500-505. [Crossref]

6. Fick D, Kolanowski A, Waller J (2007) High prevalence of central nervous system medications in community-dwelling older adults with dementia over a three-year period. Aging Ment Health 11: 588-595. [Crossref]

7. Morandi A, Lucchi E, Turco R, Morghen S, Guerini F, et al. (2015) Delirium superimposed on dementia: A quantitative and qualitative evaluation of patient experience. J Psychosom Res 79: 281-287. [Crossref]

8. Bellelli G, Morandi A, Zanetti E, Bozzini M, Lucchi E, et al. (2014) Recognition and 
management of delirium among doctors, nurses, physiotherapists, and psychologists: an Italian survey. Int Psychogeriatr 26: 2093-2102. [Crossref]

9. Choi EJ, Lee H, Kim IA, Lim Y, Lee MS, et al. (2011) Delirium assessment ability of clinical nurses. Journal of Korean Gerontological Nursing 14: 167-175.

10. Lee YW, Kim CG, Kong ES, Kim KB, Kim NC, et al. (2007) A study of nurses' knowledge level and assessment experience of delirium. Journal of Korean Academy of Adult Nursing 19: 35-44.

11. Yang H (2010) Comprehension and knowledge about delirium in nurses working at long-term care hospitals or general hospitals. The Journal of Korean Academic Society of Nursing Education 16: 312-320

12. Kim MY, Eun Y (2013) Knowledge, Performance and Stress about Care for Delirium in Orthopedic Hospital Nurses. Journal of Muscle and Joint Health 20: 72-80.

13. Maneesriwongul W, Dixon JK (2004) Instrument translation process: methods review. $J$ Adv Nurs 48: 175-186. [Crossref]

14. Norwood SL (2010) Research essentials: Foundations for evidence-based practice: Prentice Hall.

15. Cho SH, Kim HR (2006) Family and paid caregivers of hospitalised patients in Korea. $J$ Clin Nurs 15: 946-953. [Crossref]

Copyright: (C2017 Kang Y. This is an open-access article distributed under the terms of the Creative Commons Attribution License, which permits unrestricted use, distribution, and reproduction in any medium, provided the original author and source are credited. 